\title{
Optimization of Process Parameters in Electro-Magnetic Welding of D9 Tube to SS316 L (N) Plug
}

\author{
Satendra Kumar ${ }^{*}$, G. K. Dey², Archana Sharma ${ }^{1,2}$ \\ ${ }^{1}$ Homi Bhabha National Institute, Bhabha Atomic Research Center, Mumbai, India \\ ${ }^{2}$ Bhabha Atomic Research Center, Mumbai, India \\ Email: *satendra@barc.gov.in, gkdey@barc.gov.in, arsharma@barc.gov.in
}

How to cite this paper: Kumar, S., Dey, G.K. and Sharma, A. (2020) Optimization of Process Parameters in Electro-Magnetic Welding of D9 Tube to SS316 L (N) Plug. Open Access Library Journal, 7: e6346. https://doi.org/10.4236/oalib.1106346

Received: April 22, 2020

Accepted: May 23, 2020

Published: May 26, 2020

Copyright $\odot 2020$ by author(s) and Open Access Library Inc.

This work is licensed under the Creative Commons Attribution International License (CC BY 4.0).

http://creativecommons.org/licenses/by/4.0/ (c) (i) Open Access

\begin{abstract}
In electro-magnetic welding (EMW) process, optimization of process parameters is very important aspect. Optimization process leads to generation of mechanically and metallurgically sound interface weld without overstressing tool coil and electromagnetic welding equipment. This work investigates the effect of four important process parameters (Magnetic field in coil ID, Frequency of current pulse, Taper angle of SS316 L (N) plug and Stand-off distance between D9 tube and SS316 L (N) plug) on weld quality and their optimization. Multiple experiments were conducted to arrive at optimized value of above mentioned process parameters which generated heat effected zone free, mechanically and metallurgically qualified interface weld of reasonable length. The welded interface revealed a wavy morphology of $35-40 \mu \mathrm{m}$ as maximum crest height and lowest helium leak rate of $4 \times 10^{-10} \mathrm{~m} \cdot \mathrm{bar} \cdot \mathrm{L} / \mathrm{s}$. Experimental results have proved that $27 \mathrm{~T}$ magnetic field is needed in coil ID to produce optimum weld quality at interface. Experimental data has proved that at higher frequency, similar quality of electro-magnetic welding can be obtained at lower bank energy. Experimental results have also proved that taper angle of $8^{\circ}$ produces weld interface at lowest possible magnetic field in coil ID. It is also proved experimentally that $0.5 \mathrm{~mm}$ stand-off distance produces better weld length as compared to no stand-off distance and $1.0 \mathrm{~mm}$ stand-off distance.
\end{abstract}

\section{Subject Areas}

Applied Physics, Electrochemistry

\section{Keywords}

Electromagnetic Welding, Magnetic Field, Ringing Frequency: Taper Angle, 
Stand-Off Distance, Wavy Pattern and Helical Disc Coil

\section{Introduction}

Electro-magnetic welding (EMW) is a solid state welding process that is achieved by a magnetic pressure pulse causing a high-velocity impact on two materials, resulting in a true metallurgical bond. One of the great advantages of MPW is that it is suitable for joining dissimilar metals having vast variation in their mechanical properties [1]. There is no heat affected zones (HAZ) on colliding surfaces if process parameters are optimized and the clean surfaces formation is obtained as a result of jet formation during collision. $\mathrm{Wu}$ and Shang [2] have reported that joining of many dissimilar advanced high-strength metals enhanced for customized-engineered properties is uniquely possible through electromagnetic welding (EMW) process.

In recent years this technology has gained a lot of popularity in welding of rector components. Kumar et al. [3] have demonstrated electro-magnetic welding of flared D9 tube to cylindrical SS316 L (N) plug. On industrial front joining of a lot of automobile components are being tried using electro-magnetic welding technology. Electro-magnetic welding (EMW) technology has been used for the Lamborghini Hurricane car hood production for the first time and the process details have been announced at "Doors and Closures in Car Body Engineering 2014, 5th International Benchmarking Conference 2014". Although it may be slightly different from the mass production line because of low production volume, it is a good example of EMW application in commercial automobile production [4].

Kwee, I. et al. have demonstrated electromagnetic welding of copper to aluminum sheets. They have studied the effects of Welding Parameters on the Structural and Mechanical Properties of Aluminum and Copper Sheet Joints. The interfacial morphology and mechanical properties of the $\mathrm{Al} / \mathrm{Cu}$ joints were analyzed and related to the welding process parameters. Weld zone exhibited a wavy interface. The interfacial layers had a thickness ranging from $2-39 \mu \mathrm{m}$, interface waviness amplitude up to $11 \mu \mathrm{m}$ and contained $31-75 \mathrm{wt} \% \mathrm{Cu}$. The interfacial layer thickness and the weld length are determined by both the discharge energy and the stand-off distance [5] [6].

Explosive welding (EXW) and electro-magnetic welding (EMW) are identical in process. Verstraete, J. et al. have emphasized that knowledge of EXW can be used for understanding of the joining principles and the effect of process parameters on electro-magnetic welding. In EXW, both wavelength and amplitude of the wavy joint interface will increase with increasing flyer velocity. In EMW both taper angle and flyer velocity are not constant. This results in a continuously changing interface along the length of the weld unlike EXW [7].

In the present experimental work, EM welding of alloy D9 tube to SS316 L (N) solid plug is focused while arriving for optimum parameter value to get metal- 
lurgical weld at interface. Two types of electro-magnetic systems were chosen to vary frequency of operation. Helium leak test and microstructure analysis have been performed to identify the bonding interface and its characteristics. Data were recorded for weld length, crest height of wavy pattern and helium leak rate for quantitative comparison.

\section{Methodology}

\subsection{Experimental Set-Up and Material Properties}

In electromagnetic welding system, energy is stored in the form of capacitive energy. High intensity magnetic field is achieved by discharging the stored capacitive energy to the electro-magnetic (EM) coil using a spark gap switch. Huge magnetic pressure is generated inside the vicinity of EM welding coil by interaction of EM coil magnetic field and eddy currents induced over the surface of work piece (flyer tube). Figure 1 shows photograph of $40 \mathrm{~kJ} / 20 \mathrm{kV}$ EM bank and all important system parameters are listed in Table 1. Figure 2 shows photograph of $180 \mathrm{~kJ}, 75 \mathrm{kV}$ EM bank and all important parameters are listed in Table 2. Figure 3(a) shows photograph of EM coil, Figure 3(b) shows drawing of D9 tube-SS316 L (N)-Copper driver combination, Figure 3(c) shows cross section of D9 tube-SS316 L (N)-Copper driver combination and Figure 3(d) shows placement schematic of D9 tube-SS316 L (N) plug-Cu driver combination with respect to EM coil. Stand-off distance and taper angle of SS316 L (N) plug are marked in Figure 3(d). The combination shown in Figure 3(b) is coaxially placed within the coil ID. The interaction of transient magnetic field of EM coil and induced eddy currents on the conductive driver surface generates a radial Lorenz force, which is repulsive in nature. As a consequence, the driver tube pushes the flyer tube (D9 tube) strong enough to drive it beyond its yield strength, resulting in the formation of a very strong weld with SS316 L (N) plug.

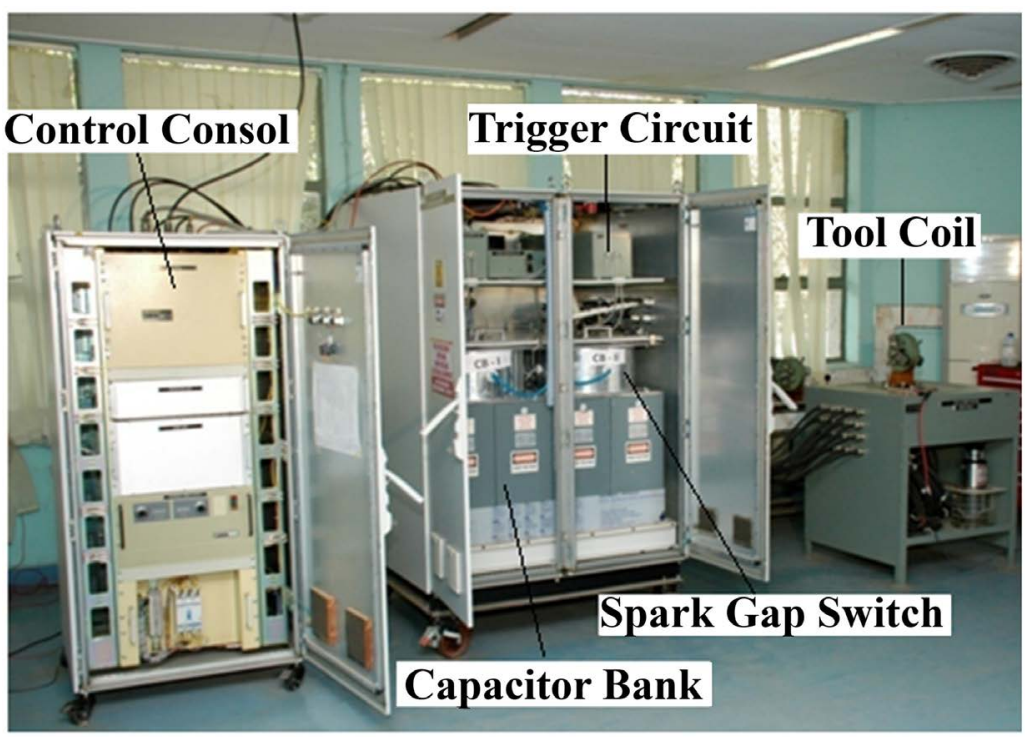

Figure 1. 40 kJ, 20 kV, EMM System. 
Table 1. 40 kJ, 20 kV EMM bank parameters.

\begin{tabular}{ll}
\hline \multicolumn{1}{c}{ System Rating } & \multicolumn{1}{c}{ Operating Parameters } \\
\hline Total Capacitance- $2244 \mu \mathrm{F}$ & \\
Charging Voltage (Max.)-20 kV & Charging Voltage- $(13-16 \mathrm{kV})$ \\
Maximum Current- $400 \mathrm{kA}$ & Coil Current- $(250-285 \mathrm{kA})$ \\
Voltage Reversal- $80 \%$ & Operating Energy- $(13-20 \mathrm{~kJ})$ \\
System Inductance- $320 \eta \mathrm{H}$ & Operating Frequency- $(10-16) \mathrm{kHz}$ \\
Rep Rate-1 shot in 5 minutes & B field- $(32-40$ Tesla $)$ \\
No. of Modules-2 & Pressure Generated-up to $640 \mathrm{Mpa}$ \\
Capacitors in each module-8 & \\
Short circuit frequency-20 kHz & \\
\hline
\end{tabular}

Table 2. 180 kJ, 75 kV EMM bank parameters.
System Rating
Total Capacitance- $64 \mu \mathrm{F}$
Charging Voltage (Max.)-75 kV
Maximum Current-1 MA
Voltage Reversal-80 \%
System Inductance-95 $\eta \mathrm{H}$
Rep Rate-1 shot in 5 minutes
No. of Modules- 4
Capacitors in each module- 4
Short circuit frequency- $>70 \mathrm{kHz}$
Operating Parameters
Charging Voltage- $(21-23 \mathrm{kV})$
Coil Current- $(250$ - $265 \mathrm{kA})$
Operating Energy-(13 - $17 \mathrm{~kJ})$
Operating Frequency-(36 - $41 \mathrm{kHz})$
B field-(32 - 40 Tesla)
Pressure Generated-up to $640 \mathrm{Mpa}$

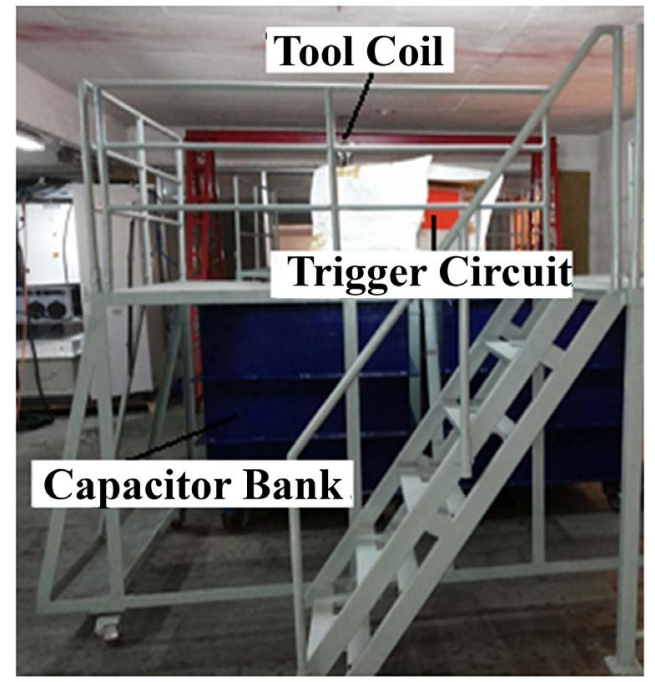

Figure 2. 180 kJ, 75 kV, EMM System.

Table 3 shows dimensions of EM coil, D9 tube, SS316 L (N) plug and copper drivers. Table 4 shows chemical composition of D9 tube and SS316 L (N) plug [8] [9]. 


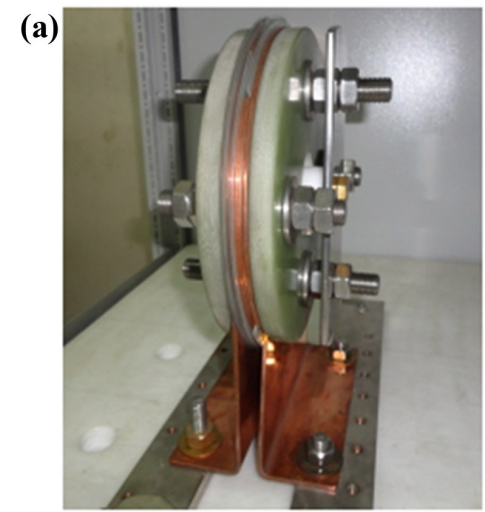

(d)

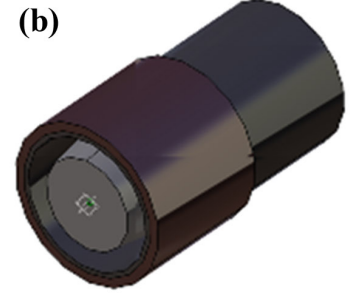

(c)

Figure 3. Photograph of EMM coil, D9 tube-SS316 L (N) plug-Cu driver combination and placement schematic.

Table 3. Parameters of EM coil, D9 tube, SS316 L (N) plug and copper driver.

\begin{tabular}{|c|c|c|}
\hline EM coil Parar & $\begin{array}{l}\text { D9 Tube and SS316 L }(\mathrm{N}) \\
\text { plug parameters }\end{array}$ & Copp \\
\hline $\begin{array}{l}\text { Material-Be-Cu } \\
\text { (Be-1.8\% - 2\%) } \\
\text { Number of discs-4 } \\
\text { Effective turns }(N)-3 \\
\text { Inductance- } 400 \eta \mathrm{H} \\
\text { Active length }(L)-18 \mathrm{~mm} \\
\text { Conductivity-30\% IACS } \\
\text { Yield strength- } 800 \mathrm{Mpa}\end{array}$ & $\begin{array}{l}\text { D9 Tube:- }(20 \% \mathrm{CW}) \\
\text { OD }\left(2 r_{0}\right)-21.4 \mathrm{~mm} \\
\text { ID- } 20 \mathrm{~mm} \\
\text { Thickness }(t)-0.7 \mathrm{~mm} \\
\text { Length- } 40 \mathrm{~mm} \\
\text { Yield strength }(Y)-795 \mathrm{Mpa} \\
\text { Conductivity }(\sigma)-2 \% \text { IACS } \\
\text { SS316 L N) Plug:- } \\
\text { Dia-19.95 mm } \\
\text { Length-30 mm } \\
\text { Taper Length-18 mm } \\
\text { Taper Angle- } 5^{\circ}-10^{\circ} \\
\text { Stand-off distance- } 0.0,0.5 \mathrm{~mm}, 1.0 \mathrm{~mm}\end{array}$ & $\begin{array}{l}\text { Case-1 }(40 \mathrm{~kJ} \text { Bank }) \\
\text { OD-23.4 mm } \\
\text { ID-21.4 } \\
\text { Length-23 mm } \\
\text { Case-2 }(180 \mathrm{~kJ} \text { Bank }) \\
\text { OD-22.6 mm } \\
\text { ID-21.4 } \\
\text { Length-23 mm } \\
\text { Vacuum Annealing } \\
\text { Temperature rise upto } 550^{\circ} \mathrm{C} @ \\
5^{\circ} \text { C/min and Natural cooling } \\
\text { afterwards }\end{array}$ \\
\hline
\end{tabular}

Table 4. Chemical composition of D9 tube and SS316 L (N) plug.

\begin{tabular}{ccc}
\hline Element & D9 Tube & SS316 L (N) \\
\hline $\mathrm{C}$ & 0.04 & 0.03 \\
$\mathrm{Ni}$ & 15.5 & 14 \\
$\mathrm{Cr}$ & 14.04 & 18 \\
$\mathrm{Mo}$ & 2.25 & - \\
$\mathrm{Ti}$ & 0.26 & - \\
$\mathrm{Si}$ & 0.61 & 0.33 \\
$\mathrm{Mn}$ & 1.78 & 1.88 \\
$\mathrm{~N}$ & 0.0037 & 0.044 \\
$\mathrm{Fe}$ & Balance & Balance \\
\hline
\end{tabular}


Two types of EM banks were used in experimentation to achieve two frequencies which are very apart with each other. Once EM banks are fabricated, it is practically very difficult to achieve multiple distinct operating frequencies which are quite apart with each other. If we try to achieve higher frequency by reducing bank capacitance, we need to charge EM bank to higher voltage to achieve weld thus increasing voltage stress on EM coil. Here in our experiments we have used two types of EM banks to achieve two frequencies which are very apart with each other [10].

\subsection{Weld Qualifying Criterion}

For the application of alloy D9-SS316 L (N) tubular joints in fast breeder reactors (FBRs), one of the primary criterions is related to leak tightness of weldment. All welded samples are subjected to helium leak test to assure this primary requirement using mass spectrometer leak detector (MSLD). Samples having leak rate in the range of $10^{-9} \mathrm{~m} \cdot \mathrm{bar} \cdot \mathrm{L} / \mathrm{s}$ are only selected for further investigation. Weld length and interface waviness (crest height) were analyzed using optical microscope. Following qualitative criterion were used to compare the weld quality of different samples.

1) Samples showing better leak rate are considered superior than others.

2) Samples showing larger weld length are considered superior than others.

3) Samples showing large crest heights are considered superior in case weld length is same.

\section{Results and Discussions}

EM weld quality depends upon many parameters. For a given flyer-clad combination and optimally designed Electro-magnetic coil many parameters effect the weld quality. We have used a four disc Be-Cu EM coil for welding of D9 tube to SS316 L (N) plug. This combination of flyer and clad has been chosen as it requires most challenging EM coil design due to high yield strength (795 Mpa) of D9 material and at the same time very poor electrical conductivity of D9 tube (2\% IACS). Effect of four major parameters has been studied experimentally on this flyer-clad welding combination. These parameters are listed below.

1) Magnetic field in coil ID.

2) Frequency of current pulse.

3) Taper angle of SS316 L (N) plug.

4) Stand-off distance between D9 tube and SS316 L (N) plug.

\subsection{Magnetic Field in Coil ID}

There is a minimum magnetic field $\left(B_{\min }\right)$ which need to be generated to push flyer tube (D9) into plastic region and at the same time provide sufficient kinetic energy to attain required collision velocity to attain metallurgical bonding with plug. This minimum magnetic field $\left(B_{\min }\right)$ depends upon thickness of tube $(t)$, yield strength of flyer tube $(Y)$, mean radius of flyer tube $\left(r_{0}\right)$ and electrical con- 
ductivity of flyer tube $(\sigma)$. Since D9 has very poor electrical conductivity so it is necessary to use conductive driver ring over D9 tube. Aluminum (AL) and copper $(\mathrm{Cu})$ are two electrically conductive and commercially cheap materials. Here a conductive copper driver of suitable thickness has been used as a driver material. Copper driver will absorb all magnetic pressure and will drive D9 tube over SS316 L (N) plug. As there is no gap between copper driver and D9 tube, they are not welded together during process [11].

\subsubsection{Computation of Required $B$ Field $\left(B_{\min }\right)$ for D9-SS316 L (N) Weld Combination}

We Calculate $B_{\min }$ to be generated in coil-work piece gap using Equation (1)

$$
\left(B_{\min }^{2}-B_{0}^{2}\right) / 2 \mu_{0}=10 Y\left(t / r_{0}\right) \text { where } B_{0}=B_{\min } e^{(-t / \delta)}
$$

Here $t(0.7 \mathrm{~mm})$ is thickness of $\mathrm{D} 9$ tube and $r_{0}(10.7 \mathrm{~mm})$ is mean radius. Current skin depth $(\delta)$ depends upon frequency of current pulse $(f)$ and conductivity $(\sigma)$ of D9 material. It is given by Equation (2). $Y\left(t / r_{0}\right)$ is pressure required to just yield the clad tube. A factor of 10 is incorporated to compensate all electrical losses, mechanical losses, thermal losses and providing required kinetic energy to flyer tube for metallurgical welding.

$$
\delta=\sqrt{\frac{1}{\pi f \mu \sigma}}
$$

D9-SS316 L (N) combination $B_{\min }$ is 36.1 Tesla.

\subsubsection{EM Coil Current vs. Magnetic Field Intensity $\left(B_{\min }\right)$ in Centre of Coil ID}

Magnetic field generated in coil ID depends upon coil current and its geometrical parameters (number of turns, active length, pitch, sector angle and ID of coil). For a helical disc coil which can be approximated to solenoid coil, it is expressed as Equation (3).

$$
B_{\min }=\mu_{0} k N I / L
$$

where $k$ is geometrical correction factor. It depends upon aspect ratio $(L / D)$ of coil, in present case its value is 0.50 (for coil active length $18 \mathrm{~mm}$ and coil diameter $25.4 \mathrm{~mm}$ ). Calculated value of $B_{\min }$ is $27.2 \mathrm{~T}$ without job piece.

FEM simulation of magnetic field in coil ID is done using ANSYS software with and without job piece in coil ID. Current pulse supplied to EM coil is having $260 \mathrm{kA}$ peak value and $13 \mathrm{kHz}$ ringing frequency. Simulated $B$ field without job piece is represented in Figure 4(a). The absolute value of the field in the middle of the coil is 27.1 Tesla. A cross confirmation was done using Faraday rotation technique (Figure 5) and it measured as 10.2 Tesla per $100 \mathrm{kA}$ closely confirming the above results.

\subsubsection{Magnetic Field (B) Enhancement by Work Piece}

Coil magnetic field can be experimentally measured only when there is no work piece inside coil ID. When we place the work piece inside coil ID there is no gap 

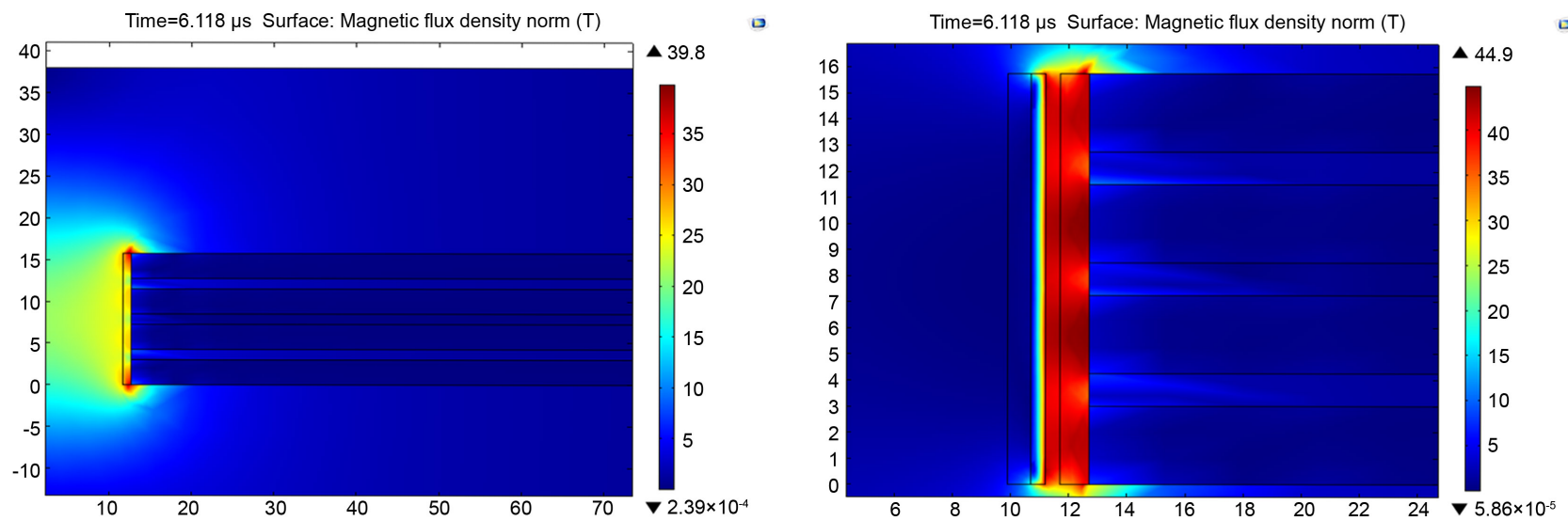

Figure 4. " $B$ field” concentration after placement of job-piece. (a) Central $B$ Field (27T) without job piece; (b) $B$ field after placing job-piece $(37 \mathrm{~T})$.

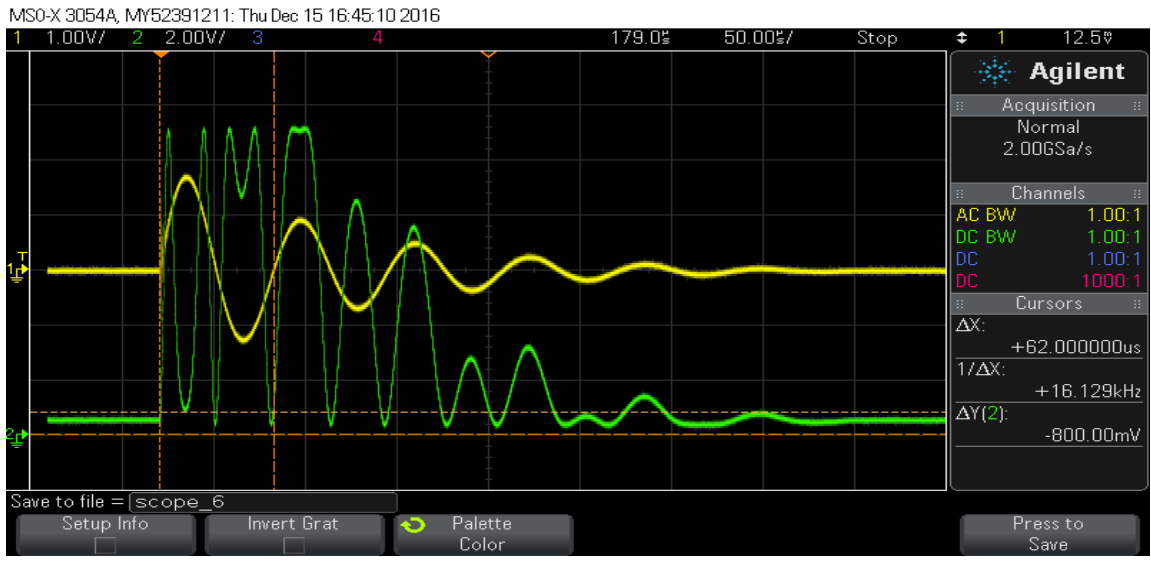

Figure 5. $B$ field measurement by Faraday rotation.

to place any instrument of smallest possible size. Simulation shows that there is more than $30 \%$ increase in $B$ field after placing the work piece. It is due to confinement of magnetic field lines in a smaller annular volume after placing work piece. Magnetic field enhancement depends upon frequency of current pulse as well as conductivity of coil material. For better conductivity coil materials enhancement improves. It also improves if current frequency is increased. Figure 4(b) shows the $B$ field concentration from 27 Tesla to 37 Tesla after placement of job-piece-driver combination in coil ID. Magnetic field uniformity is also achieved in coil ID by placing job-piece-driver combination.

\subsubsection{Experiments and Discussions}

$\mathrm{EM}$ coil of $\mathrm{Be}-\mathrm{Cu}$ is having high yield strength in the range of $800 \mathrm{Mpa}$ and electrical conductivity around 30\% IACS. Coil currents below $250 \mathrm{kA}$ didn't produce leak proof joint (better than $10^{-9} \mathrm{~m} \cdot \mathrm{bar} \cdot \mathrm{L} / \mathrm{s}$ ) also there was only a point weld observed at locations near to the tapered end. Coil currents were varied from 250 $\mathrm{kA}-280 \mathrm{kA}$. At $250 \mathrm{kA}$, we got leak rate in the range of $10^{-9} \mathrm{~m} \cdot \mathrm{bar} \cdot \mathrm{L} / \mathrm{s}$ and weld length of $2-3 \mathrm{~mm}$.

Coil life at $250 \mathrm{kA}$ current level is around 10 shots as pressure exerted in coil 
ID is comparatively less. As current is increased, there is marginal increase in leak tightness and weld length is improved to $4-7 \mathrm{~mm}$. Current levels (>250 kA) coil life is severely compromised. Coil life is just 3 shots at $270 \mathrm{kA}$ current, it is having just one shot life at current levels of $280 \mathrm{kA}$. Experimental results at different current levels are summarized in Table 5. At times many samples produced above $250 \mathrm{kA}$ current didn't qualify leak test; it was mainly due to non-concentricity in sample placement and improper holding of job ends by integrated fixture. Optimization of magnetic field in coil ID or optimization of coil current for a single frequency is necessary to enhance EM coil life as well as life of capacitor bank. This optimization becomes more critical when we deal with EM welding of high yield strength materials. Figure 6(a) shows welded sample of D9 tube to SS316 L (N) plug along with copper driver. Figure 6(b) shows photograph of saw effect in coil ID of Be-Cu coil after 8 shots at $260 \mathrm{kA}$ current.

On increasing frequency of current pulse, required magnetic field is achieved at lower current levels. $270 \mathrm{kA}$ current at $13 \mathrm{kHz}$ ringing frequency produces

Table 5. Effect of central magnetic field of EM coil on leak tightness and weld length.

\begin{tabular}{|c|c|c|c|c|c|c|}
\hline Sr. No & $\begin{array}{c}\text { EM Coil } \\
\text { Type }\end{array}$ & $\begin{array}{l}\text { Coil Current } \\
\text { (kA) }\end{array}$ & $\begin{array}{l}\text { Central B Field } \\
\text { (T) (without job) }\end{array}$ & $\begin{array}{l}\text { Leak rate } \\
(\mathrm{m} . \text { bar.L/s) }\end{array}$ & $\begin{array}{l}\text { Freq. } \\
(\mathrm{kHz})\end{array}$ & Weld length/Coil life \\
\hline 1 & $\mathrm{Be}-\mathrm{Cu}$ & 240 & 25 & $<10-9$ & 13 & No weld \\
\hline 2 & $\mathrm{Be}-\mathrm{Cu}$ & 250 & 26 & $\sim 10-9$ & 13 & $\begin{array}{c}\text { Weld length }[2-3 \mathrm{~mm}] \\
\text { Coil life } \sim 10 \text { shots }\end{array}$ \\
\hline 3 & $\mathrm{Be}-\mathrm{Cu}$ & 260 & 27 & $\sim 10-9$ & 13 & $\begin{array}{c}\text { Weld length }[4-7 \mathrm{~mm}] \\
\text { Coil life }[6-8 \text { shots }]\end{array}$ \\
\hline 4 & $\mathrm{Be}-\mathrm{Cu}$ & 270 & 28 & $\sim 10-9$ & 13 & $\begin{array}{l}\text { Weld length }[5-8 \mathrm{~mm}] \\
\text { Coil life-3 shots }(\max )\end{array}$ \\
\hline 5 & $\mathrm{Be}-\mathrm{Cu}$ & 280 & 29 & $\sim 10-9$ & 13 & $\begin{array}{c}\text { Weld length [5- } 8 \mathrm{~mm}] \\
\text { Coil life-single shot }\end{array}$ \\
\hline 6 & $\mathrm{Be}-\mathrm{Cu}$ & 260 & 28 & $\sim 10-9$ & 39 & $\begin{array}{c}\text { Weld length }[5-8 \mathrm{~mm}] \\
\text { Coil life- } 3 \text { shots }\end{array}$ \\
\hline 7 & $\mathrm{Cu}$ & 260 & 27.5 & $\sim 10-9$ & 14 & $\begin{array}{l}\text { Weld length }[4-7 \mathrm{~mm}] \\
\text { Coil life-single shot }\end{array}$ \\
\hline
\end{tabular}

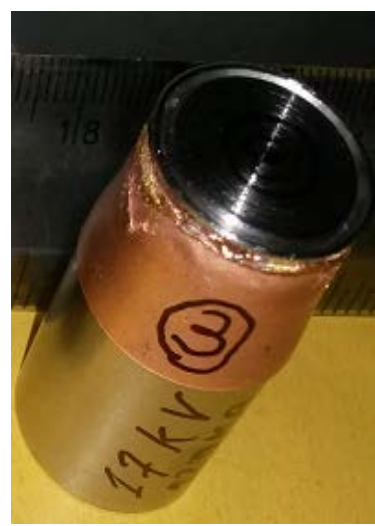

(a)

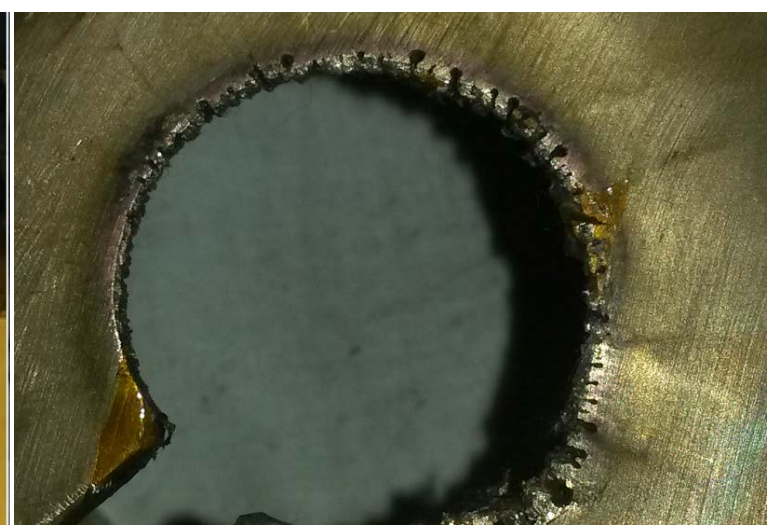

(b)

Figure 6. (a) Welded sample; (b) Saw effect in Be-Cu EM coil after 8 shots. 
same magnetic field as $260 \mathrm{kA}$ current at $39 \mathrm{kHz}$ frequency. Using better conductivity coil material, required magnetic field can be achieved at lower current levels as well. $260 \mathrm{kA}$ current in copper (ETP grade) coil can generate equal amount of magnetic field as $265 \mathrm{kA}$ current in $\mathrm{Be}-\mathrm{Cu}$ coil. It can be concluded that magnetic filed in the range of $26-27 \mathrm{~T}$ is optimum magnetic field for EM welding of D9 tube-SS316 L 9N) combination.

\subsection{Frequency of Current Pulse}

Frequency of current pulse has a very distinct role in EM welding. First and foremost there is a direct relationship of thickness of conducting material and frequency of current pulse. If skin depth (expressed in Equation (2)) is more than the thickness of material to be welded than part of the magnetic field (and pressure subsequently) will pass through the flyer tube. In limiting condition thickness of driver can be taken equal to skin depth at frequency of operation. Given a choice, frequency should be chosen in such a way that skin depth is half of the thickness of flyer tube/conducting driver. Frequency of current pulse is derived from total inductance and capacitance of the system. For a given set of coil-job combination, EM coil inductance is fixed. As EMM system design is a complex task so too much capacitance and inductance variation is not possible for a job like D9-SS316 L(N) as it require high magnetic pressure for welding (>500 Mpa).

In present research experimentation work is done on two frequencies $(13 \mathrm{kHz}$ and $39 \mathrm{kHz}$ ) keeping coil-job combination same. These two frequencies are derived from two set of EM systems listed above. Weld quality was assessed in both cases for same amount of peak current. All distinct advantages of high frequency operation are listed and discussed below.

\subsubsection{Enhanced $B$ Field and Pressure}

At high frequency current skin dept is small; causing coil currents to flow very close to driver material and producing more magnetic fields in the vicinity. It translates into more magnetic pressure and better coupling with job-piece. Too much increase in frequency is also not recommended as it leads to ablation of flyer tube (or driver material) as eddy currents are limited to very small thickness.

\subsubsection{Distinct Waviness at Weld Interface}

At high frequencies distinct waviness is observed at weld interface in optical micrograph. Metallurgically it interprets as a better mechanical locking and excellent welding. Although it may generate few melt pockets at interface if pressure is not controlled to optimum value. Hardness (VHN) of interface region is improved when weld surface changes from flat to wavy on increasing frequency at same coil currents.

\subsubsection{Reduced Thermal Loading on Driver and Coil}

At low frequency energy dissipated in coil resistance $\left(I^{R} t\right)$ is high as time $(t)$ is large. It leads to conductive driver melting and subsequent damage in coil ID 
insulation which reduces life of EM coil. At high frequency electrical resistance $(R)$ of current path increases due to reduction of skin depth. Electrical resistance is proportional to square root of frequency $(f)$ and time period $(t)$ is inversely proportional to frequency.

\subsubsection{Experiments and Discussions}

Experimental Findings are tabulated in Table 6, which clearly explains the advantage of high frequency in terms of low current requirement to generate same " $B$ " field in coil ID.

In Table 7, waviness in micrograph at high frequency is shown which is more prominent as compared to low frequencies for same " $B$ " field.

Table 6. Effect of frequency in EM welding.

\begin{tabular}{ccccccc}
\hline Sr. No EM Coil Type & $\begin{array}{c}\text { Coil Current } \\
(\mathbf{k A})\end{array}$ & $\begin{array}{c}\text { Central B } \\
\text { Field }\end{array}$ & $\begin{array}{c}\text { Leak rate } \\
(\mathbf{m} \cdot \text { bar } \cdot \text { L/s })\end{array}$ & $\begin{array}{c}\text { Freq. } \\
(\mathbf{k H z})\end{array}$ & Comments \\
\hline 1 & $\mathrm{Be}-\mathrm{Cu}$ & 260 & 28 & $\sim 10-9$ & 39 & High Freq \\
2 & $\mathrm{Be}-\mathrm{Cu}$ & 264 & 29 & $\sim 10-9$ & 39 & High Freq \\
3 & $\mathrm{Be}-\mathrm{Cu}$ & 250 & 26 & $\sim 10-9$ & 13 & Low Freq \\
4 & $\mathrm{Be}-\mathrm{Cu}$ & 260 & 27 & $\sim 10-9$ & 13 & Low Freq \\
5 & $\mathrm{Be}-\mathrm{Cu}$ & 270 & 28 & $\sim 10-9$ & 13 & Low Freq \\
6 & $\mathrm{Be}-\mathrm{Cu}$ & 280 & 29 & $\sim 10-9$ & 13 & Low Freq \\
\hline
\end{tabular}

Table 7. Comparison of Wavy characteristic at low frequency and high frequency in EM welding.

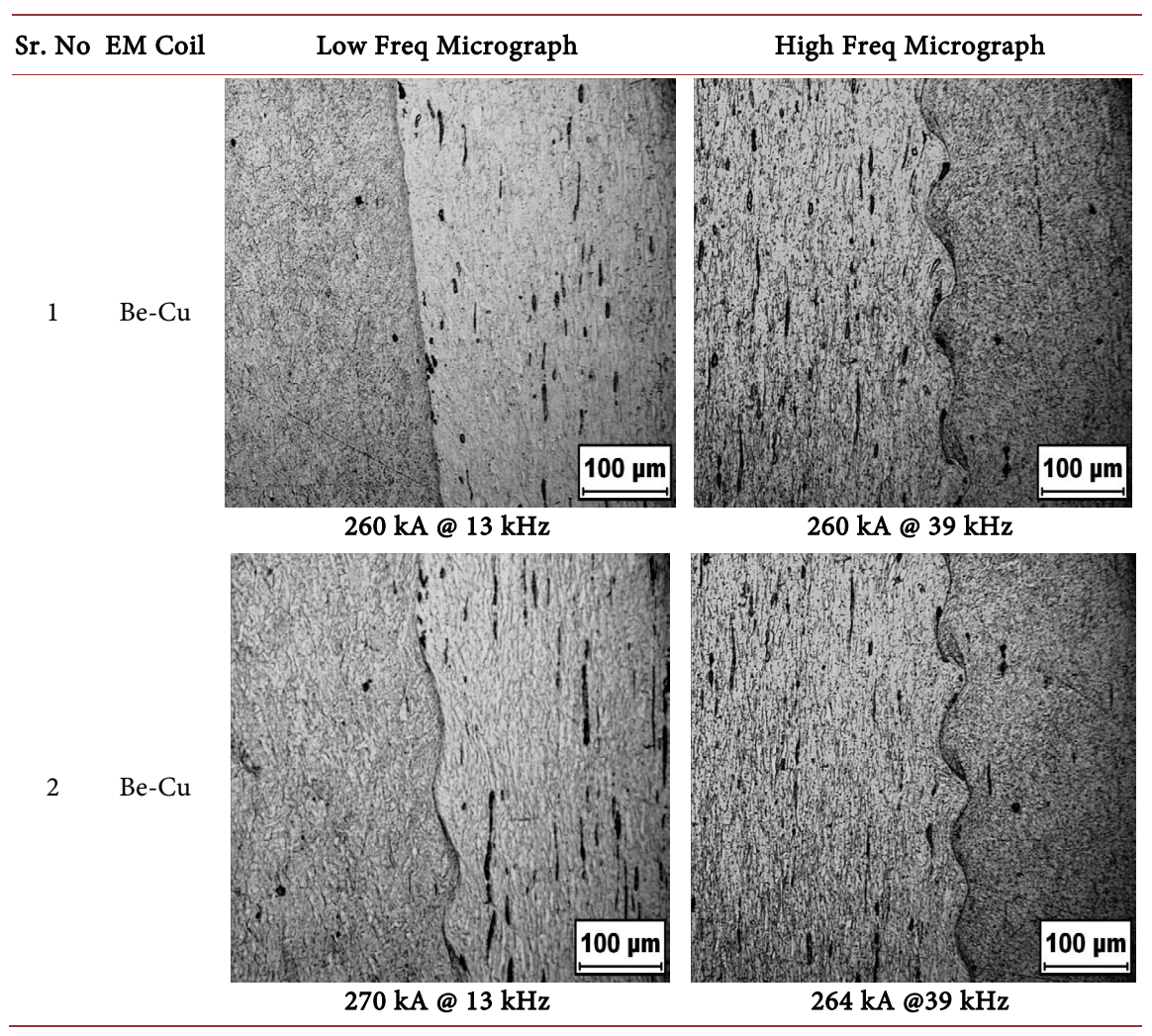




\subsection{Taper Angle of Plug}

\subsubsection{Requirement of Taper Angle}

An Electromagnetic force brings two colliding surfaces together progressively at a collision front. The collision front's velocity must be lower than the speed of sound in the materials, so that the shock wave precedes the bond being formed. If not, the shockwave would interfere with the contacted surfaces preventing a bond occurring. The interfacial pressure at the collision front must exceed the yield strength of the materials, so that plastic deformation will occur.

A jet of metal is formed just ahead of the collision front, comprising of the two component surfaces, which is finally ejected from the interface. The surfaces and any surface contaminants are removed in the jet. Behind the collision front, the now clean surfaces bond, under extreme pressure, in the solid state. In cross section, the materials usually bond together in an undulating wave form. Taper angle provides initial jetting action for surface cleaning as well as successively increasing standoff distance to facilitate attainment of required collision to flyer tube [12] [13].

\subsubsection{Variation of Taper Angle}

Taper angle of plug was varied from 5 degree to 10 degrees in a length of $18 \mathrm{~mm}$. At 10 degree taper angle we get a maximum clear separation of tube and plug as $3.0 \mathrm{~mm}$ while at 5 degree taper angle separation was just $1.48 \mathrm{~mm}$. A schematic of SS316 L (N) plug is shown in Figure 7(a). EM pressure exerted on cu driver (over D9 tube) is shown in Figure 7(b). At 5 degree taper angle more current (or pressure) is needed to get leak proof weld; it is due to restricting the travel distance of D9 tube to lower end. D9 tube is hitting SS316 L (N) plug before it acquired peak velocity. At 10 degree taper angle it also requires more current to produce leak proof weld; it is due to the fact that current (pressure) pulse has diminished and D9 tube has not yet collided with the SS316 L (N) plug.

Experiments were done to obtain an optimum taper angle. An optimum taper angle was experimentally derived for least possible current $(250 \mathrm{kA} @ 13 \mathrm{kHz})$ to produce leak proof joint having longer weld length.

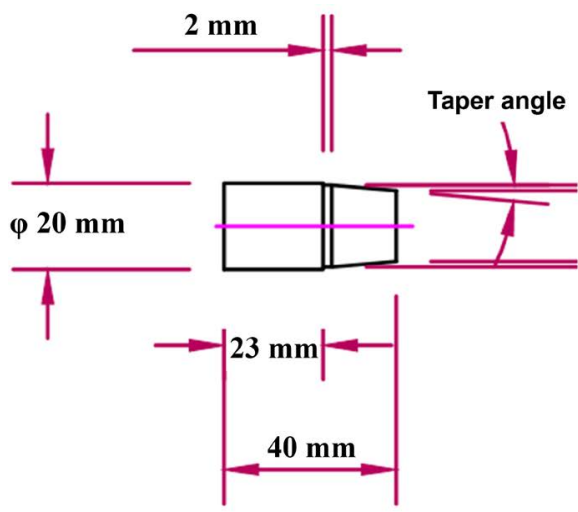

(a)

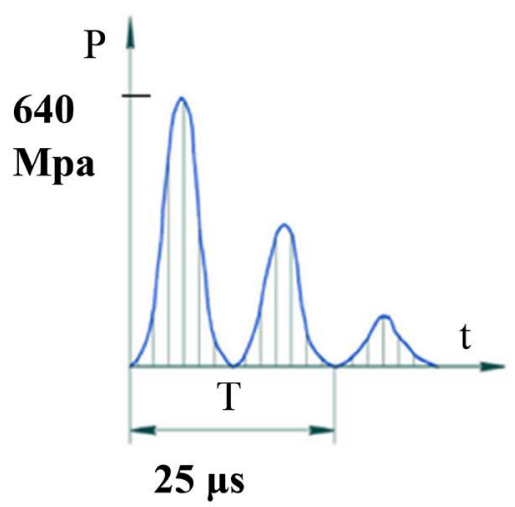

(b)

Figure 7. (a) Dimensions of SS316 L (N) plug; (b) Pressure pulse on flyer tube. 


\subsubsection{Experiments and Discussions}

Table 8 summarizes experimental findings of data obtained by varying taper angle from $5^{\circ}$ to $10^{\circ}$. These experiments were conducted on Be-Cu EM coil using $250 \mathrm{kA}$ current @ $13 \mathrm{kHz}$ ringing frequency. There was no weld length at taper angles 5, 6 and 10 degree. Point weld at rear end of plug was observed at 7 and 9 degree taper angles. At 8 degree taper angle weld length of $2-3 \mathrm{~mm}$ was observed. Taper angle optimization is fully geometry dependent exercise. Plugs having higher dimensions will give better results at lower taper angles and vice versa.

\subsection{Stand-Off Distance}

\subsubsection{Requirement of Stand-Off Distance}

The standoff distance is the distance between parts (flyer tube and plug) prior to the application of pressure pulse. This gap must exist at each point along desired weld length, because, when magnetic pressure is applied on the flyer tube, it must have space to gain velocity and acquire sufficient kinetic energy that is going to be transformed into impact energy. In order to have good welding between both metals, there is an optimum value of stand-off distance, which varies according to the welding materials and geometry. When stand-off distance deviates from that value, the velocity and the kinetic energy reduce, leading to a reduction in the weld strength and the width of the weld. If the stand-off distance is low, collision takes place before the flyer metal could reach the maximum velocity. On the other hand, for higher stand-off distance, the velocity drops to a lower value at the time of collision. In terms of capacitor bank energy, the higher the gap, the higher should be the bank energy in order to obtain a good quality weld. Figure 7 (a) shows typical geometry of plug having $0.5 \mathrm{~mm}$ stand-off distance.

\subsubsection{Experiments and Discussions}

Three set of stand-off distance variations were studied experimentally; $0.0 \mathrm{~mm}$, $0.5 \mathrm{~mm}$ and $1.0 \mathrm{~mm}$. Experiments were conducted at $250 \mathrm{kA}$ current @ $13 \mathrm{kHz}$ ringing frequency and 8 degree taper angle using $\mathrm{Be}-\mathrm{Cu}$ coil. Experimental findings are summarized in Table 9. Having optimized all other parameters at

Table 8. Effect of taper angle on weld quality for same " $B$ field".

\begin{tabular}{ccccc}
\hline Sr. No & $\begin{array}{c}\text { Taper Angle } \\
\text { (degrees) }\end{array}$ & $\begin{array}{c}\text { Coil (Be-Cu) } \\
\text { B field (Tesla) }\end{array}$ & $\begin{array}{c}\text { Leak rate } \\
(\mathbf{m} \cdot \mathrm{bar} \cdot \mathrm{L} / \mathrm{s})\end{array}$ & $\begin{array}{c}\text { Weld Length } \\
(\mathbf{m m})\end{array}$ \\
\hline 1 & 5 & 26 & $4 \times 10^{-3}$ & Nil \\
2 & 6 & 26 & $2 \times 10^{-4}$ & Nil \\
3 & 7 & 26 & $1 \times 10^{-4}$ & Point \\
4 & 8 & 26 & $5 \times 10^{-8}$ & $2-3 \mathrm{~mm}$ \\
5 & 9 & 26 & $6 \times 10^{-6}$ & Point \\
6 & 10 & 26 & gross & nil \\
\hline
\end{tabular}


Table 9. Effect of stand-off distance on weld quality.

\begin{tabular}{ccccc}
\hline Sr. No. & EM coil current $(\mathrm{kA})$ & Taper angle & Stand-off $(\mathrm{mm})$ & Weld length \\
\hline 1 & 250 & $8^{\circ}$ & Nil & Nil \\
2 & 250 & $8^{\circ}$ & $0.5 \mathrm{~mm}$ & $2-3 \mathrm{~mm}$ \\
3 & 250 & $8^{\circ}$ & $1.0 \mathrm{~mm}$ & Point weld \\
\hline
\end{tabular}

$250 \mathrm{kA}$ current (i.e. Magnetic field in coil ID, Frequency of current pulse and taper angle of plug), stand-off distance was varied. There was no weld length at $0.0 \mathrm{~mm}$ stand-off distance. At $0.5 \mathrm{~mm}$ stand-off distance $2-3 \mathrm{~mm}$ weld length was observed in optical micrograph. Though there was a point weld at rear end of D9 tube in case of $1.0 \mathrm{~mm}$ stand-off distance, problem of tube thinning and tearing was observed at step location.

\section{Conclusions}

In the present study, optimization of process parameters has been established experimentally for EM welding of D9 tube to SS316 L (N) plug. Based on the investigation results and discussions, following are the important conclusions:

1) Magnetic field in coil ID is an important parameter for EM welding. It should be optimized to achieve higher coil life and higher capacitor bank life. Magnetic field in coil ID depends upon electrical conductivity of coil material and frequency of current pulse. Magnetic field increases on increasing conductivity of coil material and it also increases with frequency of current pulse. For EM welding of D9-SS316 L (N) optimized magnetic field in coil ID is in the range of $[26-27 \mathrm{~T}]$ for $\mathrm{Be}-\mathrm{Cu}$ coil.

2) Frequency of current pulse is crucial parameter in EM welding. Ideally frequency should be chosen in such a way that skin depth at that frequency is half of the thickness of flyer tube/driver sleeve. It is experimentally proved that 39 $\mathrm{kHz}$ frequency requires low coil current to generate same magnetic field in coil ID as compared to current at $13 \mathrm{kHz}$ frequency. A distinct advantage of higher frequency is generation of waviness at weld interface, which results in stronger bond.

3) Taper angle provides initial jetting action for surface cleaning as well as successively increasing standoff distance to facilitate attainment of required collision to flyer tube. Taper angle was varied from 5 degree to 10 degree. At 5 degree taper angle more current (or pressure) is needed to get leak proof weld; it is due to restricting the travel distance of D9 tube to lower end. D9 tube is hitting SS316 L (N) plug before it acquired peak velocity. At 10 degree taper angle it also requires more current to produce leak proof weld; it is due to the fact that current (pressure) pulse has diminished and D9 tube has not yet collided with the SS316 L (N) plug. Taper angle of 8 degree was optimum value for D9-SS316 L (N) EM welding.

4) In order to have good welding between flyer tube and plug, there should be optimum value of stand-off distance, which varies according to the welding ma- 
terials and geometry. When stand-off distance deviates from that value, the velocity and the kinetic energy reduce, leading to a reduction in the weld strength and the width of the weld. If the stand-off distance is low (nil in present case), collision takes place before the flyer metal could reach the maximum velocity. On the other hand, for higher stand-off distance ( $1.0 \mathrm{~mm}$ in present case), the velocity drops to a lower value at the time of collision. Experimentally $0.5 \mathrm{~mm}$ distance is found to be optimum for D9-SS316 L (N) welding combination.

\section{Acknowledgements}

Authors would like to thank Mr. R. K. Rajawat, Former Associate Director, Beam Technology Development Group, Bhabha Atomic Research Center (BARC), Mumbai for his continuous support and guidance. Authors are thankful to P. C. Saroj, M. R. Kulkarni, Hitesh Choudhary and Tanmay Kolge for useful discussions during experimentations. Authors are also thankful to Dr. A. Laik and K. Shrikant for their help in optical microscopy of welded samples. Authors are also thankful to Dr. Shaju Albert for providing material support and valuable guidance.

\section{Conflicts of Interest}

The authors declare no conflicts of interest regarding the publication of this paper.

\section{References}

[1] Lueg-Althoff, J., Gies, S., Tekkaya, A.E., Bellmann, J., Beyer, E. and Schulze, S. (2016) Magnetic Pulse Welding of Dissimilar Metals in Tube-to-Tube Configuration. Proceedings of the 9 th International Welding Symposium of Japan Welding Society, Tokyo, Japan, 11-14 October 2016, 87-90.

[2] Wu, X. and Shang, J. (2014) An Investigation of Magnetic Pulse Welding of $\mathrm{Al} / \mathrm{Cu}$ and Interface Characterization. Journal of Manufacturing Science and Engineering, 136, Article ID: 051002. https://doi.org/10.1115/1.4027917

[3] Kumar, S., Dey, G. and Sharma, A. (2019) An Investigation on Weldability of Flared D9 Tube to Cylindrical SS316L (N) Plug Using Electro-Magnetic Compression Welding. Open Access Library Journal, 6, 1-11. https://doi.org/10.4236/oalib.1105465

[4] https://www.bmax.com/magnetic-pulse-welding/

[5] Kwee, I., Psyk, V. and Faes, K. (2016) Effect of the Welding Parameters on the Structural and Mechanical Properties of Aluminium and Copper Sheet Joints by Electromagnetic Pulse Welding. World Journal of Engineering and Technology, 4, 538-561. https://doi.org/10.4236/wjet.2016.44053

[6] Kwee, I. and Faes, K. (2016) Interfacial Morphology and Mechanical Properties of Aluminium to Copper Sheet Joints by Electromagnetic Pulse Welding. Key Engineering Materials, 710, 109-114.

https://doi.org/10.4028/www.scientific.net/KEM.710.109

[7] Verstraete, J., De Waele, W. and Faes, K. (2011) Magnetic Pulse Welding: Lessons to Be Learned from Explosive Welding. Proceedings of the Conference Sustainable 
Construction and Design 2011, Department of Mechanical Construction and Production, Ghent University, Ghent, Belgium, 16-17 February 2011

[8] Raj, B. (2016) Structural Materials: New Challenges, Manufacturing and Performance. IGCAR, Kalpakkam

[9] Mannan, S.L., Chetal, S.C., Raj, B. and Bhoje, S.B. (2003) Selection of Materials for Prototype Fast Breeder Reactor. Transactions-Indian Institute of Metals, 56, 155-178.

[10] Kumar, S., Desai, S.V. and Chakravarthy, D.P. (2012) Characterisation of Electromagetic Welding Equipment. International Journal of Applied Electromagnetics and Mechanics, 40, 293-300. https://doi.org/10.3233/JAE-2012-1592

[11] Kumar, S., Khan, M.R., Saroj, P.C., Sharma, A.R. and Dey, G.K. (2019) Experimental Investigation of Driver Material on Electromagnetic Welding of Alloy D9 SS Tube to SS316L(N) Plug. International Journal of Advanced Manufacturing Technology, 105, 4225-4242. https://doi.org/10.1007/s00170-019-04525-0

[12] Ben-Artzy, A., Stern, A., Frage, N., Shribman, V. and Sadot, O. (2010) Mechanism in Magnetic Pulse Welding. International Journal of Impact Engineering, 37, 397-404. https://doi.org/10.1016/j.ijimpeng.2009.07.008

[13] Moarrefzadeh, A. (2013) Finite-Element Analysis for Optimization of Explosion Welding Process. Elixir Mechanical Engineering, 56A, 13786-13787. 